\title{
Psychological Therapy for ICT Literate Older Adults in the Time of COVID-19: Perceptions on the Acceptability of Online Versus Face to Face Versions of a Mindfulness for Later Life Group
}

\author{
Adele Pacini $^{1}$, Jitka Vseteckova ${ }^{2}$ and Yannis Pappas ${ }^{3}$ \\ ${ }^{1}$ Associate Lecturer in Psychology, Faculty of Arts and Social Sciences, The Open University and Lead Clinical Psychologist for \\ Realising Ambitions Fund Project, The Gatehouse Charity East Anglia
}

${ }^{2}$ Senior Lecturer in Health and Social Care, Faculty of Wellbeing, Education and Language Studies, The Open University

${ }^{3}$ Reader in Health Service Organisation and Delivery and Head of PhD School, Institute for Health Research, University of Bedfordshire

*Corresponding author: K Jitka Vseteckova, Faculty of Wellbeing, Education and Language Studies, The Open University, United Kingdom

\section{ARTICLE INFO}

Received: 幽 September 04, 2020

Published: 幽 October 12, 2020

Citation: Jitka Vseteckova. Psychological Therapy for ICT Literate Older Adults in the Time of COVID-19: Perceptions on the Acceptability of Online Versus Face to Face Versions of a Mindfulness for Later Life Group. Biomed J Sci \& Tech Res 31(1)2020. BJSTR. MS.ID.005049.

Keywords: COVID-19; Psychological Interventions; Mindfulness; Older Adults; Wellbeing; Self-Isolation; Social Isolation

\section{ABSTRACT}

Introduction: The current study assesses the acceptability of an online mindfulness group for older adults who use ICT during COVID-19, and whether it is preferred over a face to face group.

Methods: Older adults completed a web based survey on their preference for face to face and online mindfulness groups. Participants were recruited from the community in the East Anglia region of the UK. Thirty six older adults responded to the questionnaire, aged between 65-80 years old. The survey comprised fixed response measures of preference for different formats of the mindfulness for later life group, along with qualitative responses of reasons for this.

Results: Seventy three percent of respondents wanted to attend an online version of the group, with 39\% expressing a preference for face to face interventions. Qualitative data was analyzed using thematic analysis.

Discussion: The service provision implications of these findings are discussed in the context of the COVID-19 epidemic.

\section{Introduction}

COVID-19 was declared a global pandemic on 11 March 2020 [1], causing unprecedented disruption socially, financially and organizationally to healthcare systems. Governments of the affected countries have employed a range of measures to help control the disease. Among the most frequently adopted measures against the pandemic is isolating community's most vulnerable groups. By keeping those with existing health conditions and the elderly separate from the rest of the population, it is hoped that health systems will be better able to handle an influx of COVID-19 patients while a vaccine is being developed. However, emerging research suggests that these measures are not only detrimental to the mental and physical health of older adults [2] but also ageist by their very nature [3]. Grouping everyone over a certain age together can homogenise a group, which contradicts evidence that variability in care needs increases with age [4]. Regardless of whether the isolation is self-imposed or in adherence to government regulations, studies have linked it to an increase in loneliness [5], perceived chronic pain [6] and mental health problems [7]. In a widely cited paper, Santini and colleagues [8] found evidence that isolation can lead to an increase in depression and anxiety in adults aged between 57 and 85 .

Mitigating these effects via online interaction is hampered by the perception that older adults prefer face to face over online interaction [9] the 'computer illiterate' stereotype assigned to older adults by the media [10]. Although the use of information communication technology (ICT) does decrease with age [11], studies have shown that among older people it is increasing. In 2016, $67 \%$ of older adults ( $65+$ years of age) reported use of the internet compared to $12 \%$ of older adults in 2000 [12]. Furthermore, older adults who use the internet report higher levels of psychological wellbeing [13]. 
The evidence base for the acceptability and feasibility of online interventions for older adults is promising but limited. Elsegood and Powell [14] surveyed 60 adults using mental health services, aged over 65 with anxiety and/or depression and found that $45 \%$ were interested in online CBT. Dear et al. [15] find that online CBT is beneficial for those over 60 years of age with anxiety and/or depression and results in significant reductions in symptomatology. As Xiang et al. [16] note in a recent meta-analysis, studies of this type tend to have reasonably small participant samples and reinforce the need for further investigation.

However, evidence on both acceptability and efficacy of online interventions for older adults is currently focussed on clinical populations. In the general population, research is limited to demographic data on rates of ICT use. Given that the majority of older adults are now ICT users, clearly we need to move the conversation forward to consider how acceptable online interventions are to this demographic. Little is known about the attitudes of ICT literate older adults in the general population towards online psychological interventions. In the context of COVID-19, this represents an urgent and important knowledge gap for future service planning and implementation. Mindfulness Based Interventions (MBIs) are a useful barometer for the acceptability of online intervention in this regard, straddling both clinical (e.g NICE [17]) and non-clinical populations (e.g. Future Learn [18]). The current study aimed to understand whether there is demand for an online mindfulness for later life group in older adults who use ICT, whether there is a preference for face to face mindfulness therapy, and whether age and gender impact on this. It also asks respondents to give the reasons why they find online mindfulness therapy acceptable or unacceptable.

The Research Questions were:

1) For adults over the age of 65 years who use ICT, is there demand for an online mindfulness for later life group?

2) Is there a preference for a face to face version of the mindfulness for later life group over an online group?

3) Is there an association between the age group of the respondent (65 to $69 ; 70$ to $74 ; 75$ to $80 ; 80+$ years) and the acceptability of online therapy, or preference for face to face therapy?

4) Is there an association between the gender of the respondent and the acceptability of online therapy, or preference for face to face therapy?

5) What reasons do respondents give for wanting or not wanting to attend an online mindfulness for later life group?

\section{Method}

\section{Participants \& Recruitment}

The data were collected as part of a service development programme for the Gatehouse Charity in East Anglia in response to COVID-19. A database of local services, social and healthcare groups that typically cater for older adults was collated. These included local older adult charities, peer support groups e.g. stroke peer support groups; University of the third age; local commissioning group contacts. A newspaper article was also published in the local press, and notices added to local village newsletters. The link to the study was found on the Gatehouse charity's website. The recruitment information given to respondents was that the online for later life mindfulness group was for people aged 65 years and over, and that people could participate individually or as part of a couple. Respondents were told that the Mindfulness for Later Life groups were originally proposed as face to face groups, to run in late spring 2020. But given the current COVID-19 restrictions, we were gauging interest for delivering them online. It was explained that the content of the group is based on the Mindfulness Based Stress Reduction programme developed by John Kabat Zinn, and that the format would involve six weekly meetings via Zoom, audio recordings of the practices and handouts to download. Participants had a three-week window in which to respond to the questionnaire.

\section{Data Collection}

The questionnaire was programmed and delivered through Qualtrics XM. Participants were asked to provide their age and gender. Responses were formatted on a five point likert scale with response options ranging from: 'definitely yes' to 'definitely not'. The responses were anonymous. The questions used and response options are available here: https://openss.qualtrics.com/jfe/form/ SV_2sm4eIqItwaHbOl

\section{Results}

In total, 36 people (15 Male, 21 female) responded to the survey, the average age of respondents was 70 years ( $\operatorname{std} \mathrm{dev}=4.46$, range 65-80 years).

\section{Frequency data for acceptability of online, and prefer- ence for face to face mindfulness groups}

As the survey was only offered online, respondents were necessarily people with computer access. Of these, the majority (73\%) wanted to attend the online mindfulness for later life group, $13 \%$ did not and $14 \%$ were undecided. With regards to a face to face group, 39\% prefer a face-to-face group, 34\% said they would not, $23 \%$ were undecided and $4 \%$ did not respond. 


\section{Associations between age, gender and acceptability of online or preference for face to face mindfulness groups}

Of the respondents, 17 were age 65 to $69 ; 10$ were aged 70 to 74 and nine were 75 to $80+$ years. There was no significant association between age group and the acceptability of online mindfulness therapy $\chi^{2}(8)=5.25, p=.73, \phi c=.27$. There was a significant association with regards to the age group and preference for face to face interventions, $\chi^{2}(8)=17.76, p=.023, \phi c=.50$. Further analysis showed that people in the 75-80 age group were more likely to use the 'probably yes' or 'probably not' options, whilst those in the 65-69 group were more likely to use 'definitely yes' or 'definitely not.' There was no significant association between gender and acceptability of online therapy $\chi^{2}(4)=4.33, p=0.36, \phi c==0.35$; or preference of face to face groups $\chi^{2}(4)=8.34, p=0.08, \phi c=0.48$.

\section{Qualitative Data}

Participants were asked 'What is your main reason for wanting to attend the online mindfulness for later life group?' and 'If you don't want to attend, please tell us why?" There were 27 responses to the first question, and nine to the second. Responses were analysed using thematic analysis [19]. Under participant's reasons for attending the group five themes were noted which accounted for all the responses. These related to mental health, wellbeing, COVID-19, reviving an existing mindfulness practice and personal interest.

\section{Mental Health:}

Either improving or maintaining mental health was a common reason for attending the group. The mental health difficulties identified by participants were anxiety, depression or stress:

"I have had depression before, so it would be a strategy to learn to help overcome this"

"I am affected by anxiety and stress".

\section{Well-being:}

Reasons relating to wellbeing typically spoke of wanting to attain, achieve or improve a positive mental state:

"To achieve contentment in life"

"To aid going forward in tranquility".

\section{COVID-19:}

Several participants gave responses which reflected the unique circumstances of COVID-19, particularly of social isolation in itself or the effects of it:

"Practicing social distancing in April 20 due to COVID"

Or the effects of it:

"To reduce stress in current situation (and my blood pressure!)"
One participant saw COVID-19 in a positive light:

"Always meant to try mindfulness and now is a good opportunity when have the time and process might be particularly useful"

\section{Reviving an existing practice:}

Some participants had already completed a mindfulness course and wanted to access another course; other participants wanted to re-establish a home practice:

"Reviving my practice"

"I've done a course before and found it beneficial".

One participant expressed a preference for completing the course online:

"I did go to the Buddhist centre for a term years ago and found it useful but would prefer to try it at home".

\section{Personal Interest:}

Here, participants tended to express an intellectual interest in mindfulness; in the ideas of it or learning more about it:

"Interested in the idea"

"I wish to learn more about mindfulness".

Of the participants who did not want to attend a face to face or online mindfulness group the following themes emerged: No benefit, no need, online format and already meditate.

\section{No benefit:}

For this theme participants were either sceptical of the benefits of mindfulness generally, or for themselves in particular:

"Not sure I would benefit from it"

"Not convinced about the effectiveness of mindfulness".

\section{No need}

Two participants stated that they did not feel any need to try mindfulness, either in general, or at the current point in time:

"I am comfortable with myself as I am"

"I don't feel the need to at this point in time".

\section{Online Format:}

One participant stated that they did not want to attend due to concerns over the technology used:

"On line meetings can be disrupted by the internet when it is busy".

\section{Already Meditate:}

Two participants were already meditating, and so did not feel that they needed to attend the group: 
"I have already undertaken a mindfulness course. But I think it's a brilliant idea, thank you!".

\section{Discussion}

In this study, an online mindfulness for later life group was acceptable to $73 \%$ respondents. There was a small difference between the number of people who stated that they would prefer a face-to face-group (39\%) compared to $34 \%$ who would not. There was no association between the acceptability of the online intervention, or preference for a face to face intervention with age or gender. These findings challenge the widespread assumption that older adults are both unable and unwilling to engage with online activities and health interventions [12]. It is not possible to ascertain the degree to which participant's responses were shaped by the context of COVID-19. However, qualitative analysis showed that participants typically gave personal reasons in terms of improvements in mental health, well-being or personal interest, for wanting to attend the group.

Whilst some participants gave COVID-19 and the circumstances surrounding it as their reason, they were not the majority. Indeed, one participant saw COVID-19 in a positive light in providing time to engage in a mindfulness group. Of the participants who did not want to attend the mindfulness group, only one participant stated that this was due to the online format of it. The majority of the reasons were related to mindfulness itself, either not seeing the benefit of it or not feeling a need for it.

The current data strongly speak to the idea that online interventions are acceptable to older adults who have access to online services and that there is not a strong preference for a face to face version of the same intervention. Given the potential negative effects of the extended periods of isolation on older adults during the COVID-19 pandemic [7], the fact that mindfulness was seen as an acceptable intervention by $73 \%$ of the participants of this study, favors its potential use.

As Weinberg [20] notes, the pressing issue may in fact be how to meaningfully translate the group therapy format to the screen during COVID-19. For older adults, this may raise unique barriers such as the perceived ease of use, navigation and terminology [21]. These barriers could be tackled by offering training and support to older adults. Physical barriers including diminishing eyesight and social factors such as financial restrictions, might be more difficult to overcome so future research should aim for research which examines these factors, and solutions for them, in order to more robustly bridge the gap between research and practice.

The limitation of the study is that all the respondents had access to a computer and access to online services. We do expect that, for this reason, the results are skewed in favor of the acceptability of the online intervention and future studies may address the barriers to accessing online interventions in the general population.

\section{Acknowledgement}

The SRA Health and Wellbeing Fund at the School of Health, Wellbeing and Social Care at the Open University funded the time of academic staff to write the results of this survey for publication. Dr Pacini was also funded by the West Suffolk Community Foundation to design and deliver the survey as part of a 'Realising Ambitions Fund' project.

\section{Description of Authors' Roles}

A. Pacini designed the study, collected the data and wrote the paper. J. Vseteckova and Y. Pappas edited and commented on drafts of the paper.

\section{Conflict of Interest Declaration}

None.

\section{References}

1. World Health Organization (2020) Rolling updates on coronavirus disease (COVID-19).

2. Armitage R, Nellums LB (2020) COVID-19 and the consequences of isolating the elderly. Lancet 5(5): e256.

3. Ayalon L (2020) There is nothing new under the sun: ageism and intergenerational tension in the age of the COVID-19 outbreak. International Psychogeriatrics 14: 1-4.

4. Lowsky DJ, Olshansky SJ, Battacharya J, Goldman DP (2014) Heterogeneity in Healthy Aging. The Journals of Gerontology: Series A 69(6): 640-649.

5. Patel SS, Clark Ginsberg A (2020) Incorporating Issues of Elderly Loneliness into the Coronavirus Disease-2019 Public Health Response. Disaster Medicine and Public Health Preparedness 7: 1-2.

6. Fallon N, Brown C, Twiddy H, Brian E, Frank B, et al. (2020) Adverse effects of COVID-19 related lockdown on pain, physical activity and psychological wellbeing in people with chronic pain. MedRxiv, p. 1-25.

7. Banerjee D (2020) The Impact of COVID-19 Pandemic on Elderly Mental Health. International Journal of Geriatric Psychiatry.

8. Santini ZI, Jose PE, Cornwell EY, Koyanagi A, Nielsen L, et al. (2020) Social disconnectedness, perceived isolation, and symptoms of depression and anxiety among older Americans (NSHAP): a longitudinal mediation analysis. Lancet Public Health 5(1): e62-70.

9. Thayer SE, Ray S (2006) Online communication preferences across age, gender, and duration of Internet use. CyberPsychology \& Behavior 9(4): 432-440.

10. Schreurs K, Quan Haase A, Martin K (2017) Problematizing the digital literacy paradox in the context of older adults' ICT use: Aging, media discourse, and self-determination. Canadian Journal of Communication 42(2): $1-35$

11. Vroman KG, Arthanat S, Lysack C (2015) "Who over 65 is online?" Older adults' dispositions toward information communication technology. Computers in Human Behavior 43: 156-166.

12. Anderson M, Perrin A (2017) Technology use among seniors. Washington, DC: Pew Research Center for Internet \& Technology. 
13. Chen Y, Persson A (2002) Internet use among young and older adults: Relation to psychological well-being. Educational Gerontology 28(9): 731-744.

14. Elsegood K, Powell D (2008) Online cognitive-behaviour therapy (cCBT) and older people: A pilot study to determine factors that influence willingness to engage with cCBT. Counselling and Psychotherapy Research 8(3): 189-192.

15. Dear BF, Zou JB, Ali S, Lorian CN, Johnston L, et al. (2015) Examining selfguided internet-delivered cognitive behavior therapy for older adults with symptoms of anxiety and depression: Two feasibility open trials. Internet Interventions 2(1): 17-23.

16. Xiang X, Wu S, Zuverink A, Tomasino KN, An R, et al. (2019) Internetdelivered cognitive behavioral therapies for late-life depressive symptoms: a systematic review and meta-analysis. Aging \& mental 24(8): 1196-1206.

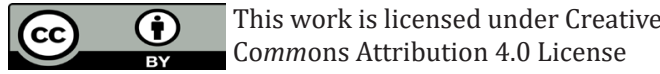

ISSN: 2574-1241

DOI: $10.26717 /$ BJSTR.2020.31.005049

Jitka Vseteckova. Biomed J Sci \& Tech Res

Submission Link: https://biomedres.us/submit-manuscript.php
17. National Institute for Health and Care Excellence (2009) Depression in adults: recognition and management.

18. Future Learn (2020) Maintaining a Mindful Life.

19. Clarke V, Braun V (2018) Using thematic analysis in counselling and psychotherapy research: A critical reflection. Counselling and Psychotherapy Research 18(2): 107-110.

20. Weinberg H (2020) Online group psychotherapy: Challenges and possibilities during COVID-19-A practice review. Group Dynamics: Theory, Research, and Practice 24(3): 201-211.

21. Adams N, Stubbs D, Woods V (2009) Psychological barriers to Internet usage among older adults in the UK. Medical Information and the Internet in Medicine 30(1): 3-17. 